Original Article

\title{
New Radiological Index for Evaluation of Pectus Deformities in Indian Population
}

\author{
S. Allwyn Joshua ${ }^{1}$, Lathika Shetty', V.S. Pare ${ }^{3} \&$ Roopa Sebastian ${ }^{4}$ \\ ${ }^{1,4}$ Assistant Professors, ${ }^{3}$ Associate Professor, Department of Anatomy, \\ ${ }^{4}$ Department of Biochemistry K. V. G. M edical College, Sullia \\ ${ }^{2}$ Professor, Department of Radiology, K. S. Hedge M edical Academy, Nitte University, M angalore, Karnataka, India.

\section{Correspondence}

\section{S. Allwyn Joshua} \\ Assistant Professor, Department of Anatomy, K. V. G. M edical College, Sullia - 574 327, Karnataka, India. \\ Mobile : +919986380713 E-mail : oxfordjosh@yahoo.com
}

\begin{abstract}
Aim : To evaluate the effectiveness of new radiological index for the diagnosis of pectus deformities in Indian population using computed tomography (CT) imaging.

Materials and methods: 60 subjects with mild to moderate pectus deformities and 100 controls with age group from 1 to 40 years were evaluated for the study. Non contrast CT images with sagittal, axial sections and 3D reconstructed images were utilized for the measurement of manubriosternal joint (MSJT) angulation as well as sterno-vertebral (SV) distance and transverse diameter (A) of chest.

Results : In controls manubriosternal joint showed mean value of $166.6 \pm 5.27$, in pectus carinatum (PC) M SJT measured about $170 \pm 5.2$ and in pectus excavatum (PE) M SJT had a value of 157.6 14.57 and internal thoracic dimensions like sterno-vertebral distance measured about mean of $91.3 \pm 18.12$ in controls, 80.24 \pm 14.57 in PE and $99.13 \pm 15.6$ in PC and transverse diameter with a mean of 208.72 \pm 33.9 in controls, 223.14 \pm 28.92 in PEand 192.2 \pm 40.96 in PC.

Conclusion : Inclusion of MSJT angulation as radiological index alongside of internationally accepted indices like sterno-vertebral distance and transverse diameter of chest would ensure comprehensive assessment of chest wall deformation and help in better understanding of sternal displacement during pectus deformities.
\end{abstract}

Keywords : manubriosternal joint; pectus excavatum; pectus carinatum; sterno-vertebral distance

\section{Introduction}

Chest deformities have an incidence of 1:1000 live births ${ }^{[1]}$ and pectus deformities are among the commonest of anterior chest wall deformities. With the introduction of minimal invasive corrective procedures for pectus deformities, increasing number of children are actively participating in cosmetic corrections ${ }^{[2]}$. Many authors have done extensive work on radio-diagnosis of pectus deformities and have given many internationally accepted radiological indices for evaluating and categorizing chest

\begin{tabular}{|c|}
\hline Access this article online \\
\hline Quick Response Code \\
\hline
\end{tabular}
wall. Among those indices, Haller's index (HI), classical vertebral index (VI), configuration index (Cl), cardiac deformity index has proven to be evaluation of pectus beneficial for objective deformities and also in quantitative assessment of internal thoracic volume ${ }^{[3-6]}$.

Prevalence and etiology of chest wall deformities, among the Indian population still remain unexplained and only scanty literature was retrieved on extensive search from the journal web ${ }^{[7]}$, probably pointing towards the lack of objective documentation about the deformity. Pectus deformities in India have failed to attract much needed medical attention, because majority of cases are asymptomatic, needing no medical or surgical intervention and hesitancy for the cosmetic corrections due to cultural and religious hindrances.

With a wide spectrum of pectus deformities seen, an attempt has been made to bring forth a new radiological index for the overall quantitative assessment of the chest wall during pectus deformities. 
The aim of the study was : a) to understand the alteration of manubriosternal joint angulation in pectus deformities, using CT images of the thorax and b) to study the influence manubriosternal joint angulation on sterno-vertebral distance and transverse diameter of the chest.

\section{M aterials and methods}

100 control subjects with an age group ranging from 1-40 years with a median of 21 , and 60 cases of mild to moderate pectus deformities with age ranging from 1-40 years with a median age of 18 were evaluated and included in the study. Informed consent was taken from patients । representatives and methodology was followed in accordance with the ethical standards of NITTE University and KVG medical college and hospital.

\section{Radiological indices measured are as follows}

Computed tomography images were utilized to enhance the precision in the measurements. Non contrast CT images of the thorax, with sagittal and axial sections have been utilized for the measurement of the indices.

First, evaluating manubriosternal joint position (MSJT): A point on the posterior end of the manubrium near its upper borber, another at the posterior end of manubriosternal joint and a third point along the posterior border of body of sternum at the level of the fourth costal notch. The posterior end of manubriosternal joint position (angulation) was determined by drawing lines to join the points marked on the plain sagittal section of CT image [fig 1$]$.

Secondly in the sagittal section of thorax, sterno-vertebral (SV) distance was measured by a line joining the posterior end of xiphi-sternal joint to the anterior part of the body of the corresponding vertebrae [fig 1] and finally in the axial section of thorax at the level of xiphi-sternal joint, transverse diameter (A) of chest was measured by the distance between the point of maximum concavity on the inner surface right rib to the point of maximum concavity on the inner surface of left rib at same level [fig 2].

\section{Inclusion criteria for controls}

a) Absence of depression or protrusion of the central portion of anterior chest wall during physical examination

b) Age group ranging from 1- 40.

c) CT scanning was performed as another type of clinical investigation

Subjects excluded were those with any affection that might interfere in the normal morphology of the thoracic cage like:

a) Early stage of vitamin D deficiency

b) Early stages of bone carcinoma of sternum or ribs

\section{Inclusion criteria for cases were}

a) Presence of depression or protrusion of anterior chest wall on physical examination

b) Age group of 1-40 years

Subjects excluded were:

1. Sternal fractures

2. Surgically corrected chest wall

3. Tilted sternum

4. Chest deformity due to underlying lung or pleural pathology and mediastinal masses

5. Asymmetrical pectus deformity and combined pectus deformity

\section{Statistical analysis}

The value has been depicted as M ean \pm SD. M ean values are compared by the method of two independent samples and significance was calculated using ' $Z$ ' test as the sample size was large and unequal. Critical range of 0.05 was set in accordance with the $5 \%$ error probability. Box-whisker's plot has been used to depict the range of M SJT angulation in controls and in pectus deformities. Pearson's rank correction test has been used to find the correlation between the manubrio-sternal joint and internal thoracic dimensions. Data was analysed using SSPS and excel software.

\section{Results}

Table 1 represents the mean \pm SD values of manubriosternal joint angulation and internal thoracic dimensions measured in controls and in pectus deformities. In controls, the age group was ranging from 140 years with median of 21 years, showed M SJT angulation 
of $166.6 \pm 6.27^{\circ}$ with a range varying from 154 to $178^{\circ}$. Internal thoracic dimensions like sterno-vertebral distance showed a mean of $91.3 \pm 18.12$, with a range of 48 to $141 \mathrm{~mm}$ and transverse diameter showed a mean of $208.72 \pm 33.9$, with a range of 90 to $264 \mathrm{~mm}$. In deformities like pectus excavatum, the MSJT measured around $157.6 \pm 8$, with a range of 134 to 170 and the sternovertebral distance having a mean of $80.24 \pm 14.57$, with range varying from 44 to $96 \mathrm{~mm}$ and also the transverse diameter showing a mean of $223.14+28.92$, with range varying from 136 to $260 \mathrm{~mm}$. lastly in pectus carinatum, MSJT had a mean of $169 \pm 5.05$, with a range varying from 152 to 174 , sterno-vertebral distance with a mean of $99.74 \pm 15.22$ and a range of 57.8 to $122.7 \mathrm{~mm}$ and lastly the transverse diameter of chest showed a mean of $196.2 \pm 36.96$, with a range of 101 to $262 \mathrm{~mm}$.

Change in the MSJT angulation and internal thoracic dimensions in pectus excavatum were highly significant in comparison with controls at a confidence of $99 \%$ and there was an evident change in MSJT angulation and internal thoracic dimensions even in pectus carinatum but were statistically insignificant. Relationship between MSJT and sterno-vertebral distance showed a positive correlation and correlation between MSJT and transverse diameter showed a negative correlation.

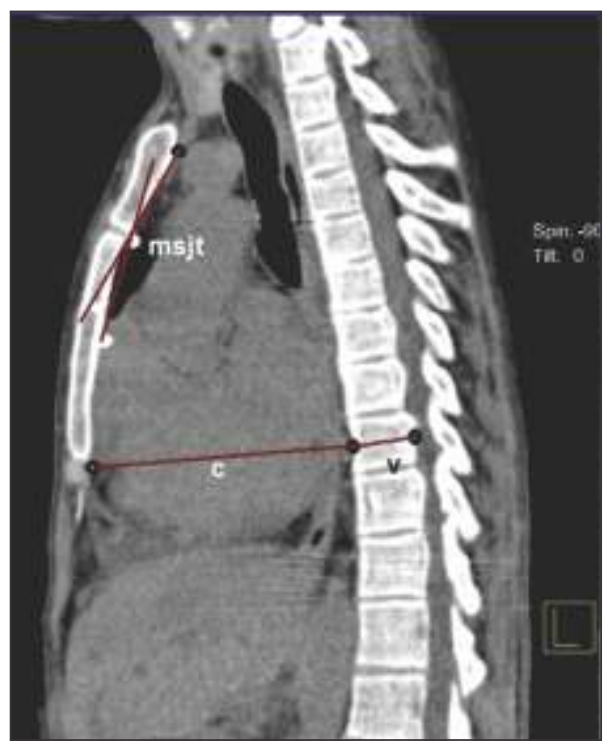

Fig. 1 : Non- contrast CT image of Thorax, sagittal view showing the measurement of Manubrio-sternal joint angulation and Sterno-vertebral distance.

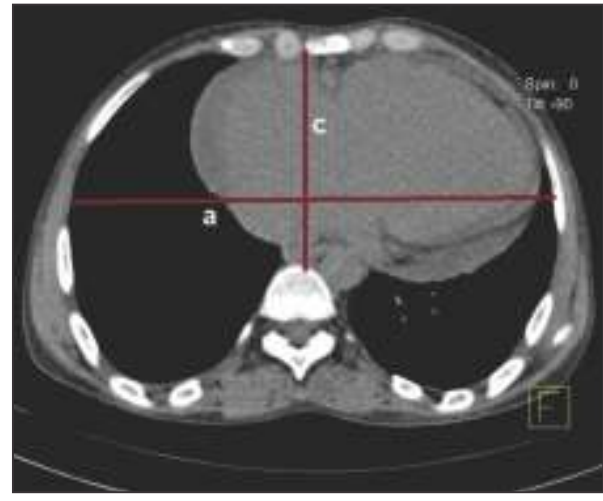

Fig. 2 : Non- contrast CT image of Thorax, axial view at the level of xiphi-sternal joint showing the measurement of Transverse diameter of chest.

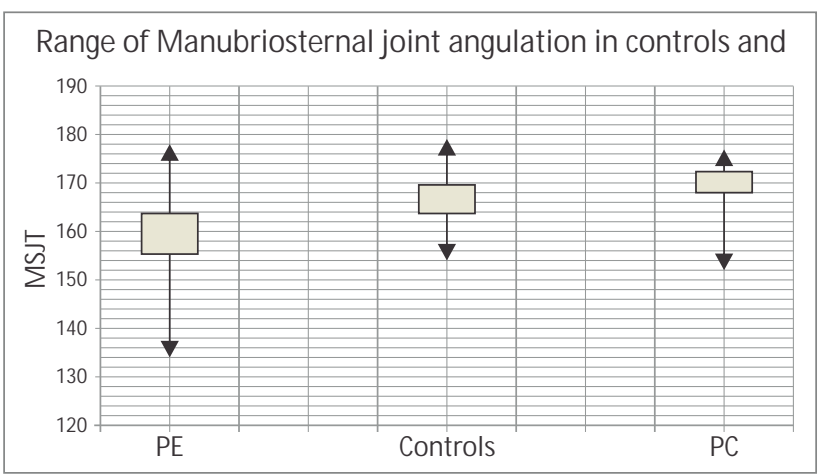

Fig. 3 : Box-whisker plot representing the Range of Manubriosternal joint angulation in controls and in pectus deformities.
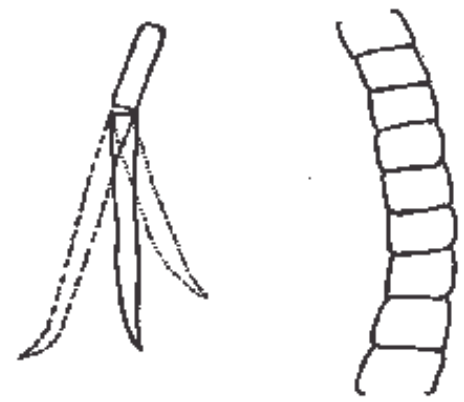

Fig. 4 : Diagrammatic representation of changes in position of Body of sternum in Pectus deformities in comparison with controls.

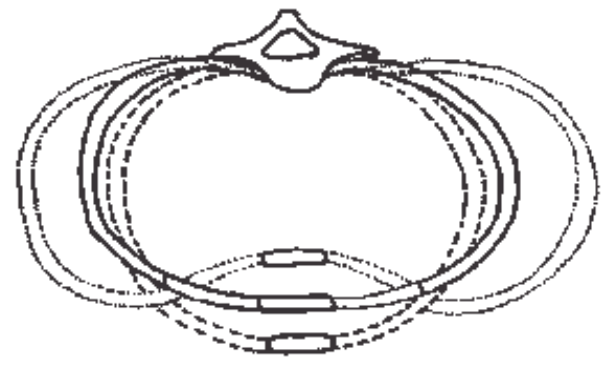

Fig. 5 : Diagrammatic representation of changes in shape of thoracic cage in Pectus deformities in comparison with controls. 
Table 1 : Manubriosternal angulation and internal thoracic dimensions in controls and pectus deformities

\begin{tabular}{|l|c|c|c|c|}
\hline & No: & MSIT $\left(^{\circ}\right)$ & SV $(\mathrm{mm})$ & $\mathrm{A}(\mathrm{mm})$ \\
\hline Controls & 100 & $166.6 \pm 6.27$ & $91.3 \pm 18.12$ & $208.7 \pm 33.9$ \\
\hline $\begin{array}{l}\text { Pectus } \\
\text { excavatum }\end{array}$ & 28 & $157.6 \pm 9.7 * *$ & $80.24 \pm 14.57 *$ & $223.14 \pm 28.92^{*}$ \\
\hline $\begin{array}{l}\text { Pectus } \\
\text { carinatum }\end{array}$ & 32 & $169.0 \pm 5.05^{*}$ & $99.74 \pm 15.22^{*}$ & $196.2 \pm 36.96$ \\
\hline
\end{tabular}

** Indicates significant at $p<0.01$ using ' $z$ ' test of unequal samples

* Indicates significant at $p \varangle 0.05$ using 'z' test of unequal samples

\section{Discussion}

Present study was an initial step towards better understanding of the pectus deformity in the Indian population. Growing awareness about the advances in diagnostics and specialised cosmetic surgeries for the correction of chest deformities has made the current study "need of the hour", if we could say so. The physiological consequences of pectus deformities of the chest wall are not generally important but the cosmetic and psychological significance has been largely ignored in the past. Present changes in cultural trends have significantly altered perception and tolerance of pectus deformities increasing the number of children who are actively seeking surgery. Pectus excavatum is readily amenable to correction using minimally invasive techniques. Good or excellent results can be expected in over $90 \%$ of cases and children should no longer be denied treatment. The optimal age for surgery is probably when the patient feels that correction is necessary ${ }^{[2]}$.

Chest deformities are among those skeletal deformities which are easily identifiable by external physical examination, but conclusive diagnosis just by physical examination may present certain limitations and can be misleading, for instance, mild variations in the configuration of costal cartilages, ribs and sternum are commonly encountered in children is a normal ${ }^{[8]}$ or type 2 pectus carinatum would give a false appearance of pectus excavatum ${ }^{[9]}$ on examination. Therefore, $\mathrm{CT}$ and MRI are not to be considered as adjunct diagnostic procedures, but as primary diagnostic tools, it would not just to facilitate comprehensive understanding of the deformity, but also to objectively categorize the deformity as mild, moderate or severe based on various indices.
Precise radiological assessment parameters delineating the limits of norm and pathology in chest deformities have not been well defined. There are many internationally accepted radiological indices, which have been used as a pre-operative objective measurement for chest deformities. Yet every index presents its own limitations and drawbacks. For example Classical vertebral index and Haller index provide information of one level of the chest and not of other levels which possibly also may be abnormal. The Configuration Index $(\mathrm{Cl})$ which is the ratio of upper vs lower chest diameter, becomes larger in pectus excavatum (especially when associated with scoliosis) and to a lesser extent also in pectus deformatum, while it became smaller in pectus carinatum. The $\mathrm{Cl}$ was especially valuable in complex chest deformities (often with axial sternal rotations) and in pectus excavatum with scoliosis where it was more often significantly changed, but does not explain more about the deformation of ribs.

With every radiological index presents its own limitations and drawbacks, precise radiological assessment parameters delineating the limits of normal and pathological have not yet been defined. Therefore, for the overall and comprehensive assessment of pectus deformities, for the first time manubriosternal joint angulation has been taken into consideration for analysisng the pectus deformities. In the development of pectus deformity sternal displacement is among the key structural alteration. Many authors are under the impression that the displacement of sternum occurs first, followed by changes in costal cartilages which has no option but to follow the sternum in its displaced position. Displacement of sternum usually begins at the junction of manubrio-sternal joint ${ }^{[10]}$.

With the evidences explaining the involvement of manubriosternal joint in pectus deformities. The study was carried out by measuring the manubriosternal angulation in controls and cases [fig 3] and its influence on alteration of mediastinal space has been assessed by evaluating sterno-vertebral distance and transverse diameter of the chest.

M anubriosternal joint measured an average of around $166^{\circ}$ 
in normal individuals, which increased to a statistically insignificant angulation of around $170^{\circ}$ in subjects with pectus carinatum, and decreased to a significant level of $156^{\circ}$ in pectus excavatum.

Cardio-respiratory dysfunction, easy fatigability and frequent respiratory infections are some of the common signs and symptoms seen in pectus deformities, which are mainly attributed to reduced intra thoracic volume and mediastinal space. Intra-thoacic space is a product of sterno-vertebral distance (antero-posterior dimension) and inter rib distance (transverse diameter of the chest). Therefore, we have measured the sterno-vertebral distance (SV) and transverse diameter of the chest (a) in normal so as to compare it with pectus deformities.

If $91.3 \mathrm{~mm}$ was the average sterno-vertebral distance in normal, this distance increased to an average of 99.13 in pectus carinatum, it reduced to a statistically significant average of $80.24 \mathrm{~mm}$ in excavatum. Therefore sternovertebral distance directly proportional to manubriosternal angulation, that is, any increase in angulation also increases sterno-vertebral distance and vice versa.

Manubriosternal angulation has direct influence on the sterno-vertebral distance. Every $1^{0}$ change in manubriosternal angulation, the sterno-vertebral distance was altered by $1.8 \mathrm{~mm}$. Change in angulation means alteration in the position of the body of sternum (gladiolus) in relation to manubrium. In conditions like pectus excavatum, the gladiolus moved closer to vertebral column and the angulation became acute at the manubrio-sternal junction in turn reducing the sterno-vertebral distance and

\section{References}

1. Willital GH, Saxena AK, Schütze U, Richter W. Chest-deformities: a proposal for a classification. World J Pediatr 2011;7(2):118-23.

2. Williams AM and Crabbe DCG. Pectus deformities of the anterior chest wall. paediatric respiratory reviews 2003; 4: 237-242

3. Kilda A Basevicius A, Barauskas A. Radiological assessment for the children with pectus excavatum. Indian .j. pediatric 2007: 74(2); 143-7.

4. Haller JA, Kramer SS, Lietman A. Use of CT scans in selection of patients for pectus excavatum surgery: a preliminary report. J Pediatr Surg 1987; 22:904-6.

5. Derveaux L, Clarysse I. Preoperative and Postoperative Abnormalities in Chest X-ray indices and in Lung Function in Pectus Deformities. Chest journal 1989; 95: 850-56

6. Miyoung K, Lee KY, Park HJ, Kim HY. Development of New Cardiac Deformity Indexes for Pectus Excavatum on Computed Tomography: Feasibility for Pre- and Post-Operative Evaluation. Yonsei M ed] 2009;0 as the angulation becomes more obtuse, as in pectus carinatum, the gladiolus moves away from the vertebra thereby increasing the sterno-vertebral distance [fig 4].

Similarly, the next internal thoracic dimension measured was the transverse diameter of the chest; we noted that as the distance between sternum and vertebra altered with aging or in pectus deformities, the transverse diameter of the chest also showed changes. The transverse diameter in controls showed a mean of $207.20 \mathrm{~mm}$, which reduced to a significant level in pectus carinatum to $189.22 \mathrm{~mm}$ and increased to a significant level in pectus excavatum to 220.26 ( $p \varangle 0.003$ ). Study by klida et al., (2009) showed the preoperative sternovertebral distance in pectus excavatum was $79.81 \pm 6.96 \mathrm{~mm}$, which increased to $97.84 \pm 17.08 \mathrm{~mm}$ during the first month after operation, $110.55 \pm 13.85 \mathrm{~mm}$ after sixth months postoperatively and the transverse diameter of chest measured a mean $273.0 \mathrm{~mm}$ preoperative, which reduced to $259.7 \mathrm{~mm}$ during the first month post-operative ${ }^{[11]}$. These alterations in the inter rib distance may be a compensatory deformation to accommodate thoracic organs Therefore the transverse diameter of the chest was inversely proportional to MSJT.

\section{Conclusion}

To completely understand the alterations of the internal thoracic dimensions in pectus deformities, Inclusion of MSJT angulation as an radiological index alongside of internationally accepted indices like sterno-vertebral distance and transverse diameter of the chest would ensure comprehensive assessment of chest wall deformation and help in better understanding of sternal displacement during pectus deformities.

\section{(3): $385-390$}

7. Puri B, Kaul SK, Harjai M M . Nuss Procedure for Pectus Excavatum - An early Experience. MJAFI 2003; 59: 316-319

8. Donnelly LF, Frush D P, Foss ] N, O'Hara S M, Bisset GS. Anterior chest wall frequency of anatomic variations in children. Radiology 1998; 212:837-40.

9. JoshuaA, Shetty L, Pare VS, Sebastian R. Chondro-manubrial deformity and bifid rib, rare variations seen in pectus carinatum: a radiological finding, Surgical and Radiologic Anatomy July 2013; 35: (5) 443-447

10. Robicsek F, Harry K. Daugherty, Donald C. Mullen, Technical Considerations in the Surgical Management of Pectus Excavatum and Carinatum. Ann thorac surg 1974; volume 18: number 36.

11. Kilda A, Lukosevicius S, Basevicius V, Jankuaskalite Z, Barauskas A. Radiological changes after Nuss operation for pectus excavatum. M edicina (Kannas) 2009;45(9):699-705 